\title{
Elevated Temperature Uniaxial Mechanical Compression Examination and Hot Rolling Characteristics of Different Steel Grades for Steel Strip Production
}

\author{
Abdulwahab J. Alsultan*, Mohamed M.Elmesmary** \\ (The Higher Institute of Energy Water Resource Department, The Public Authority for Applied Education and \\ Training,
}

\begin{abstract}
Steel material may be considered one of the most significant materials in different mechanical engineering applications because it is the foremost component in the different mechanical industries and structure of buildings . Boron steels are suitable for varied applications, Diverse elements of metals have been alloyed to steel to attain definite properties for definite uses. . For example, molybdenum can typically be used as such an alloy to ensure high strength value for low steels alloys to improve its properties, such as the mechanical properties. These grades are useful to variety of industries since improving the mechanical properties of steel will increase its performance In this paper, the Gleeble, hardness test, including the mic rostructure before and after hot stamping, will be discussed; where the stress-strain must be defined in a specific temperature range. This paper also aims to show accurate TTT and CCT diagrams for three grades that have been studied, which are steel 50, steel 52, and steel 53.
\end{abstract}

Keywords: boron steel grade; Gleeble; hardness test; materials properties; TTT diagram.

\section{INTRODUCTION}

Steel is one of the most important materials in engineering fields both in mechanical and civil fields due to the fact that it is a main component in building different structures. The technological advancements in steel have not only benefitted the construction industry, but mechanical, industrial such as automotive industries as well [1].

Optimizing steel according to various aspects is a necessity and has been the subject of different studies because of its high demand and its crucial role in the integrity of structures and components. The main objective of this text is to investigate the hot rolling characteristics of boron steels with the variance of molybdenum additions. It will also discuss elevated temperature uni-axial compression tests at multiple temperatures, and various strain rates in regards to simulating strip steel production [2].

As one of the examples for the need of such studies in mechanical engineering fields can be explained by the increasing demand for vehicle safety, as well as crash needs in industry for vehicles, the use of ultrahigh-strength steels in components of safety and structural aspects has increased. The greater need for performance can be met through the process of cold stamping using thick-gauge steel, which leads to increasing the weight of the vehicle.
Nevertheless, ultrahigh-strength steels represent a great challenge during the process of stamping due to their pronounced spring back and limited formability at room temperature [3].

The hot stamping process with the die cooling of boron steels was utilized at the end of the 1990s in order to produce particular automotive parts such as bumper beams as well as door beams. This process of using boron steel helps to avoid some of the difficulties that are related to the use of other types of material [4].

The latter part of the text will tackle the microstructure assessment after compression and cooling, which include microscopy and hardness testing. This text will also discuss which grade of steel is optimum in terms of reducing the work of roll loads.

Nowadays, boron steels are becoming popular in diverse applications. According to Frydman and Letkowska (2011) [5], boron steels which were originally used for hard and wearresistant elements are now becoming widely used in different applications due to of their technologically developed advantageous properties. In order to form steel. in different sections, one of the basic steps to be carried out is for it to undergo the rolling process. The widely used is Rolling process of forming and producing steel where metal is undergo to high compressive stress [6]. 
This compressive stress is due to the friction between the rolls and the metal surface. Hot rolling and cold rolling are the two main divisions of the process. In many material engineering books, the hot rolling process is described as the initial breakdown of ingots into blooms and billets, which are further rolled into plates, sheets, rods, bars, pipes and rails. On the other hand, cold rolling is a process carried out by means of recrystallisation temperature and introducing work hardening [6].

In our present age where everything is fast moving and mass production with high quality is a must, optimization in the manufacturing and production of a major material like steel, should focused on. Different metal elements are alloyed to steel in order to achieve certain properties for specific uses. According to [7], molybdenum is usually used as an alloy with high strength low alloy steels to boost their mechanical properties. These steel grades are becoming beneficial to different industries such as oil, gas, automotive and construction because increasing the steel's mechanical properties will increase its performance resulting in lower steel requirements [7].

According to to Nourami, et al (2012) [8] "Molybdenum (Mo) is added to improve strength, through the precipitation of fine carbides after quenching and tempering, and hard enability." They also state that molybdenum enhances the temper resistance and high temperature strength, and has been known to prevent sulfide corrosion cracking. The addition of molybdenum to boron steel is very beneficial in different applications of steel. Table 1 below shows the composition of boron steel; increasing the amount of alloying elements such as molybdenum can greatly increase its properties.

Table 1: Che mical co mposition of boron steel [9].

\begin{tabular}{|c|c|c|c|c|c|c|c|}
\hline Grade & $\mathbf{C}$ & $\mathbf{S i}$ & $\mathbf{M n}$ & $\mathbf{P}$ & $\mathbf{S}$ & $\mathbf{M o}$ & $\mathbf{N i}$ \\
\hline 50 & 0.245 & 0.22 & 1.27 & 0.008 & 0.0015 & $<.005$ & 0.01 \\
\hline 52 & 0.25 & 0.22 & 1.27 & 0.008 & 0.0019 & 0.2 & 0.01 \\
\hline 53 & 0.255 & 0.22 & 1.29 & 0.007 & 0.0019 & 0.4 & 0.01 \\
\hline
\end{tabular}

Mohbacherin (2010) [7], emphasised that it will increase the performance of steel with lower quantity requirements. This is a response to the demand for high quality steel at a reasonable price. Figures 1 and 2 below show the effects of using molybdenum for the yield strength of steel and the advantages in consumption and processing efforts. The economic benefits of this can be accounted from the reduced transportation costs and handling of materials because of the reduced load, which means greater speed, less fuel consumption and easy manage ment.

\begin{tabular}{|c|c|c|c|c|c|c|c|}
\hline Grade & $\mathbf{A l}$ & $\mathbf{B}$ & $\mathbf{C a}$ & $\mathbf{N}$ & $\mathbf{N b}$ & $\mathbf{0}$ & $\mathbf{T i}$ \\
\hline 50 & 0.039 & 0.0025 & $<.0005$ & 0.006 & $<.001$ & 0.0004 & 0.04 \\
\hline 52 & 0.039 & 0.0025 & $<.0005$ & 0.007 & $<.001$ & 0.0003 & 0.041 \\
\hline 53 & 0.039 & 0.0025 & $<.0005$ & 0.005 & $<.001$ & 0.0003 & 0.043 \\
\hline
\end{tabular}

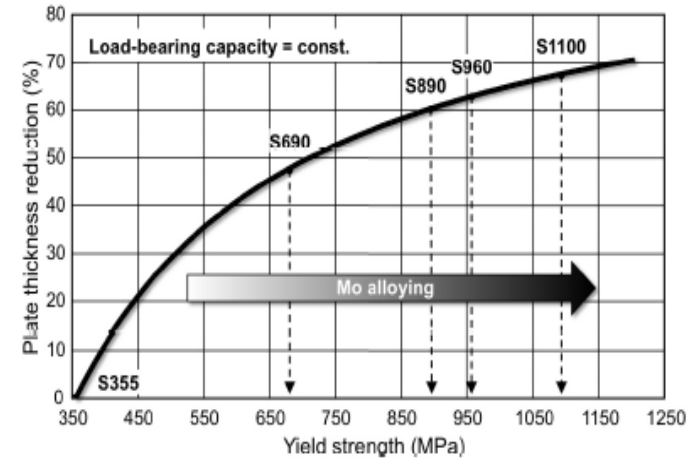

Figure 1: Effects of molybdenumalloying in the strength of steel [7].

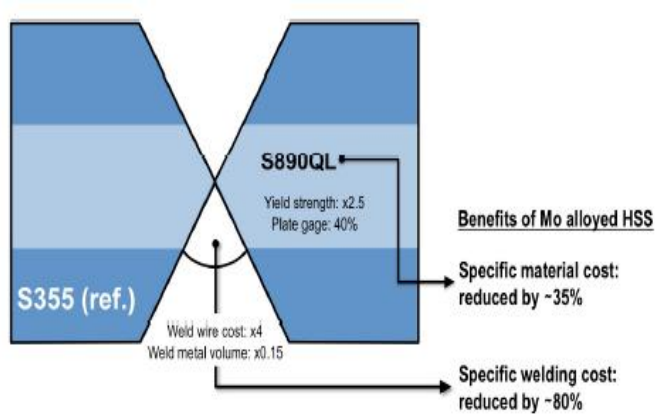

Figure 2: Benefits of using high strength steel in terms of consumption and processing efforts [7].

In the same study by Mohrbacher [7], he has discussed the effects of molybdenum during the hot rolling stage of steel. These effects includes recrystallisation, strain induced precipitation, hardenability and interphase precipitation. Figure 3 below illustrates how the addition of molybdenum to steel has a significant impact at every stage of the hot rolling process.

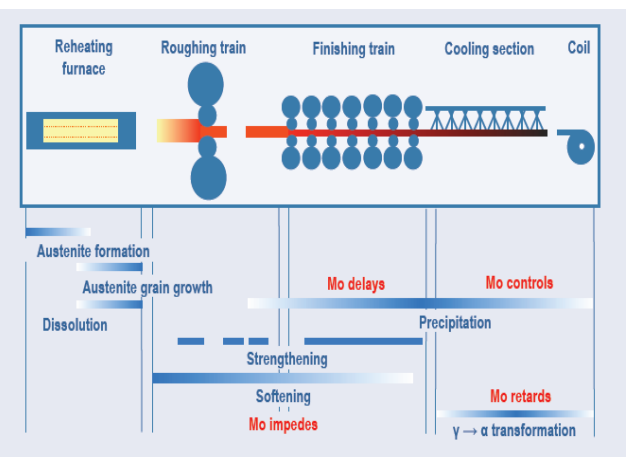

Figure 3: Main effects of molybdenum alloying during hot rolling [7]. 
Molybdenum indirectly influences the behaviour of micro alloying elements such as $\mathrm{Nb}$, Ti and $\mathrm{V}$ [7]. Niobium $(\mathrm{Nb})$ causes the slow range of recrystallisation of low carbon steel. This retarding of the rate of recrystallisation caused by molybdenum and niobium should be assisted by elevated temperatures to achieve a homogeneous, fully recrystallised microstructure within the most inter pass time in the roughing mill [7]. Figure 4 below demonstrates the influence of $\mathrm{Mo}-\mathrm{Nb}$ combinations on static recrystallisation at high temperatures.

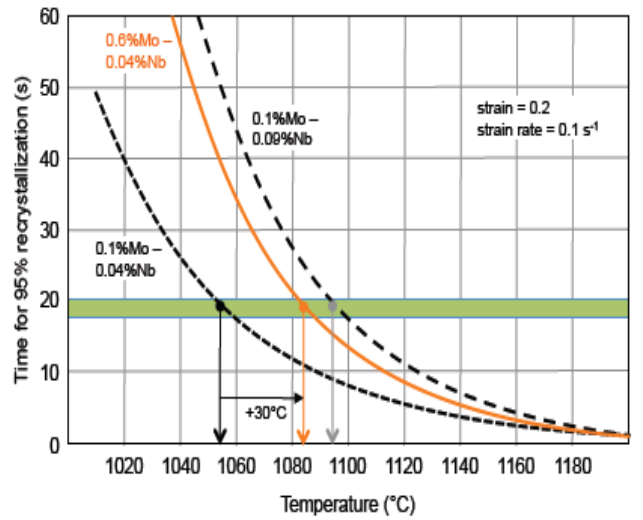

Figure 4: Effects of mo-nb combinations on static recrystallisation at high temperature [7].

Aside from the increase in the retardation of recrystallisation, another effect of the addition of molybdenum is the decrease in the amount of precipitation due to the reduction in the activity of carbon and nitrogen [7]. This action later on will result in a more refined grain when accelerated cooling is applied.

The reduction of carbon activity mentioned earlier is very advantageous to boron steels. Boron is a hardenability element used in low carbon steels, thus its effectiveness is greatly improved by the addition of molybdenum [7]. According to Deva, et al (2012), "It is well established that boron increases hardenability of steels by retarding the heterogeneous nucleation of ferrite at the austenite grain surfaces." They also state that in recent studies the effectiveness of boron on hardenability is dependent on the soaking temperature and cooling conditions [10]. According to a study by Frydman and Letkowska, proper heat treatment with this kind of steel is crucial to achieve the characteristics required, because improper temperatures will reduce the opportunity for high mechanical and chemical properties [4].

\section{MATERIALS AND EXPERIMENT}

With regards to the process of identifying which grade of boron steel will achieve optimum work roll loads, this report will discuss the Gleeble, uni-axial compressing test and the microstructure before and after hot stamping show the determination of processes for controlling work hardening is carried out by means of continuous compression tests using the Gleeble 3500 thermo mechanical simulator. The stress-strain must be defined in a particular temperature range. To simulate the different conditions of hot rolling, the specific amount of true strain should be identified.

The Gleeble system can be considered as a new age in mechanical thermal physical testing and simu lation

Characteristically, a material sample is heated besides being mechanically worked, and numerous behavior parameters of attention are recorded and measured for future analysis. After the test or simulation has been carried out, the material microstructure may likewise be inspected.

This system can deliver a cost effective method for simulating the physical performance using high temperature procedures and requests that is cheaper than testing on the full scale; furthermore, the excellent results and correlations may then be applied practically to the real application or process.

The applications for material testing have included the following [11]:

- Warm or hot tensile testing

- Warm or hot compression testing which includes:

- Unia xial co mpression

- Strain help Crack Opening (SICO)

- Plane strain compression

- $\quad$ Stress vs. strain curvatures

- Nil strength testing

- Hot ductility testing

- $\quad$ Solidification and melting

- Heat treatment or thermal cycling

Phase transformation or Dilato metry

Studies of the Stress relaxation

Stress or Creep rupture

Fatigue (Thermal, Mechanical or Thermal).

In this work, uniaxial compression will be discussed. 


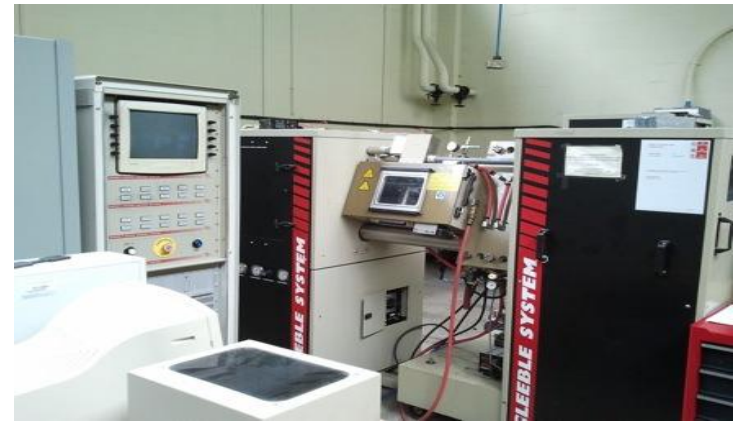

Figure 5: Uniaxial Compression machine.

The phase diagrams provided give an indication of the material microstructures that may be obtained. However, the phase diagrams assume equilibrium and they provide an idea about the material microstructure that may form because of slow cooling (small value rates of cooling). If the formation of the material microstructures wants to be understood, the rate of cooling should be taken into account, as per the diagrams for TTT and CCT.

Despite TTT diagrams being considered an effective tool for understanding the microstructure, in most practical situations, the transformations occur not isothermally but throughout continuous cooling. Hence, what is called Transformation of Continuous Cooling (CCT) diagrams, are extremely important. It is possible to move from TTT to CCT diagrams in particular circumstances, and the transformation kinetics are assumed to be based on one fraction of the transformed phases and on the temperature only.

The studies also shows the Gleeble and hardness test experimental results. Also, the microstructure will be displayed before and after the hot stamping process. The steel grades that have been used in this experiment are Steel 50, Steel 52, and Steel 53, where the base grade is 25MnB5, which contains $0.2 \%$ wt of Mo 25MnMoB5 and $0.4 \%$ wt Mo 25MnMoB5.

In the beginning, the grades were heated to $1200^{\circ} \mathrm{C}$ for $10^{\circ} \mathrm{C} / \mathrm{Sec}$. where the hold was done for $1 \mathrm{Min}$. Then the grades were cooled to $1100^{\circ} \mathrm{C}$ at $10^{\circ} \mathrm{C} / \mathrm{Sec}$. When the temperature reached $1100^{\circ} \mathrm{C}$, it was compressed to a strain of about 0.3 at a strain rate equal to 1 . After that, the double hit was performed at three different temperatures, which are 900,850 and $800^{\circ} \mathrm{C}$. The grade was cooled from $1100^{\circ} \mathrm{C}$ to one of the above temperatures at $10^{\circ} \mathrm{C} / \mathrm{Sec}$, and at the chosen temperature compressed further to a strain of about 0.2 at a strain rate of 1 twice.
The cooling process continued until the grade reached $750^{\circ} \mathrm{C}$ at $6^{\circ} \mathrm{C}$ (it was supposed to be 10 , but it was only noticed later on that it was different; however it was consistent for each test). Then the cooling to 0 at $10^{\circ} \mathrm{C} / \mathrm{S}$ (until controlled cooling was lost $\left.\sim 200^{\circ} \mathrm{C}\right)$.

\section{DATA ANALYSIS AND RESULT}

The compressive force of steel 50 at the three different temperatures is shown in the following figures:

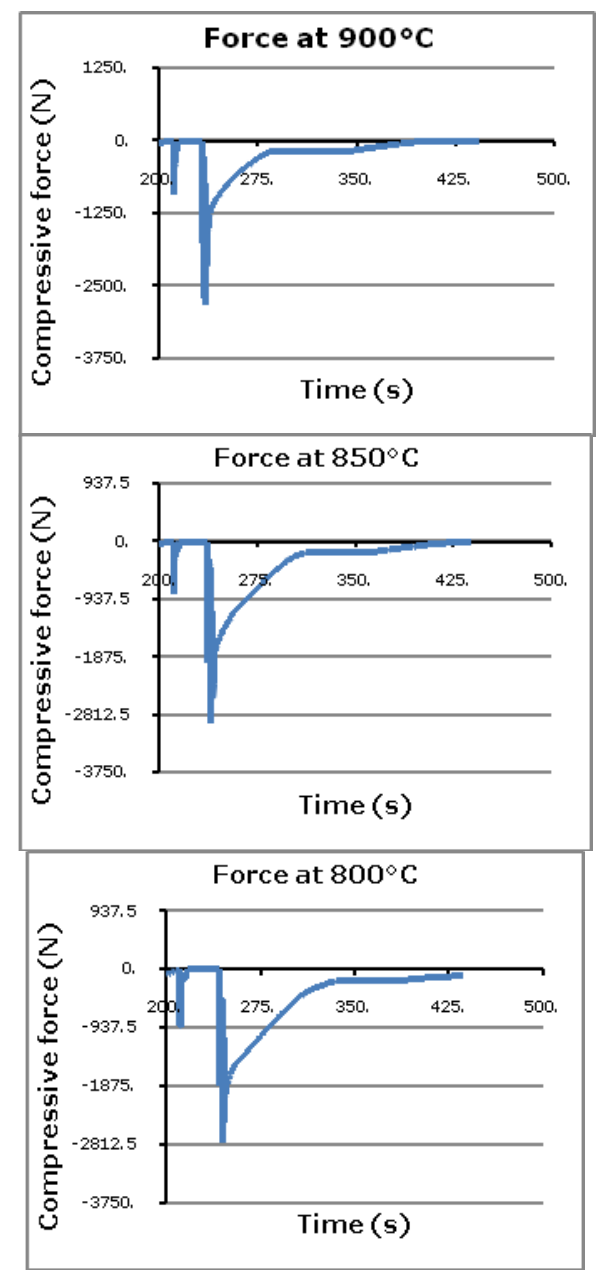

Figure 6 : Force of the steel 50.

The compressive force with time at the three different temperatures for the same grade had the same shape, where in the beginning for steel 50 , the temperature was $800^{\circ} \mathrm{C}$. The compressive force started with zero value until the time reached about $250 \mathrm{Sec}$; the compressive force decreased to a value less than $-2500 \mathrm{~N}$, then it was increased by Sharpe way until the time reached about 330s where the compressive force had an approximately constant value after that. 
The strain of the steel 50 at the three different temperatures was as in the following figures. The strain in the beginning had a value approximately equal to -0.001 then decreased by Sharpe way to reach about -0.35 and then increased with time before decreasing gradually. In the end there was an approximately constant value.

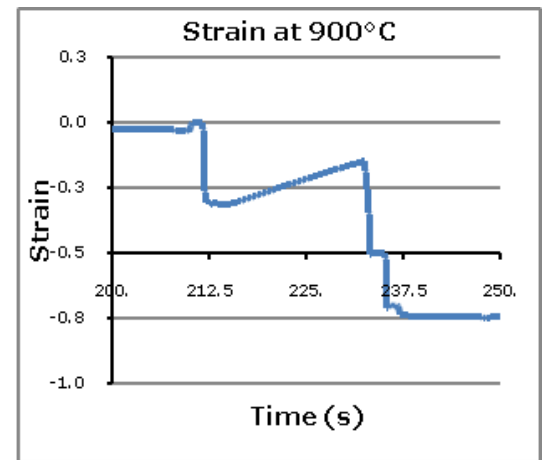

Figure 7: The strain of the steel 50

The temperature runs for steel 50 at the three different temperatures are shown in the following figures; it is clear this temperatures increased in the beginning, then had a constant value, and after that the temperatures decreased.
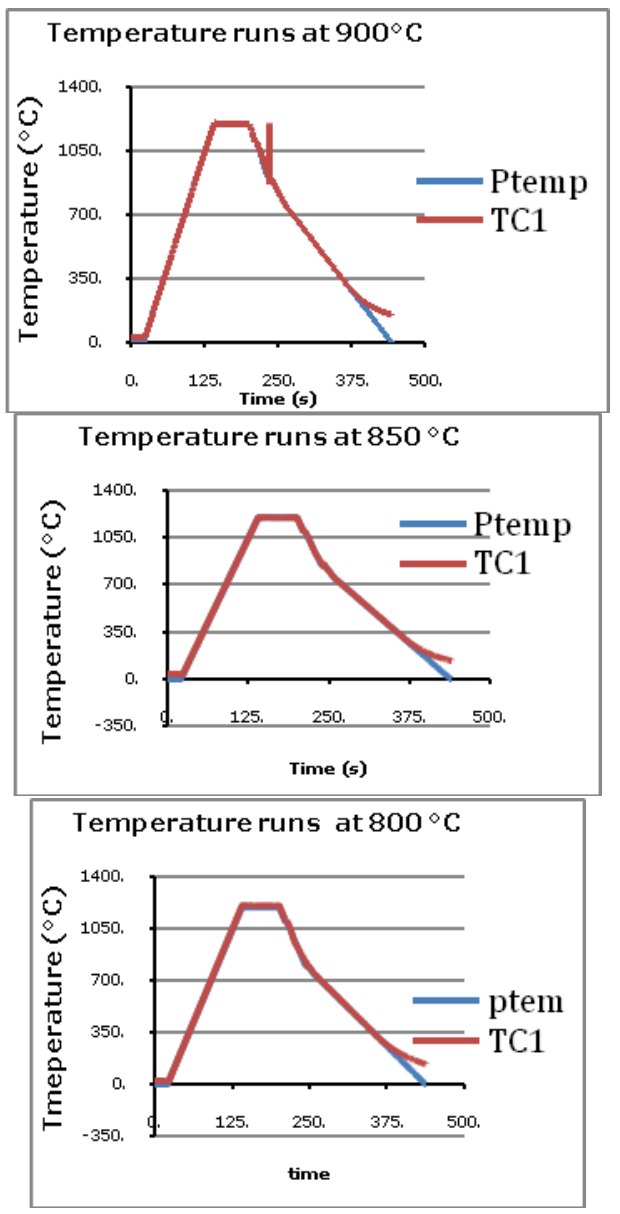

Figure 8: Temperature runs of the steel 50.
For the three different temperatures, the maximum values of the force are shown in the following table; these values all have negative signs, where the lowest value appears at $850^{\circ} \mathrm{C}$.

Table 2: The maximu $\mathrm{m}$ force for the steel 50 .

\begin{tabular}{|c|c|c|c|}
\hline Material & $\mathbf{9 0 0}^{\circ} \mathbf{C}$ & $\mathbf{8 5 0}^{\circ} \mathbf{C}$ & $\mathbf{8 0 0}^{\circ} \mathbf{C}$ \\
\hline Max Force & -2834.9 & -2949.8 & -2785.3 \\
\hline
\end{tabular}

The compressive force (N) with the temperature of the last compression for the three grades is shown in the following figure, where the compressive force for steel 50 has approximately the same value equal to about $-3000 \mathrm{~N}$; the Compressive force of steel 52 increased in the beginning and then started to decrease; while for steel 53 the compressive force increased in the beginning and then started to decrease by a small amount.

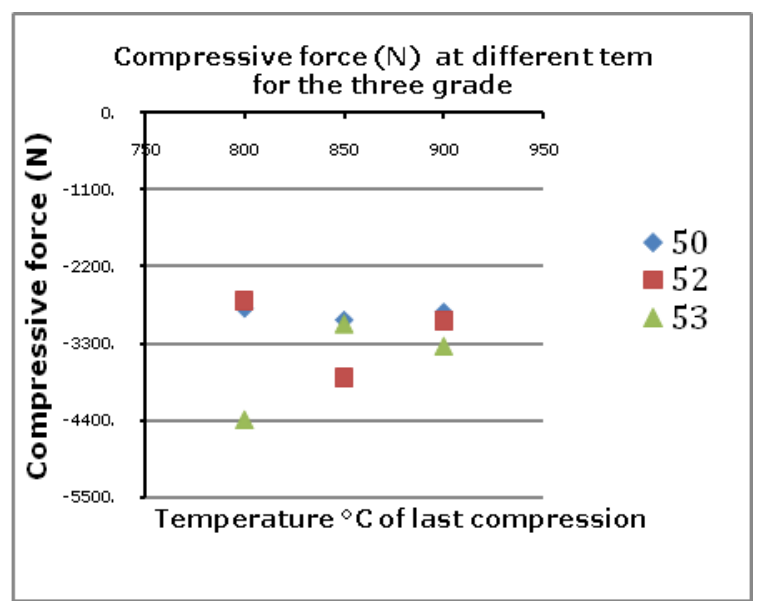

Figure 10: Compressive force (n) at different times for the three grades.

At $900^{\circ} \mathrm{c}$, for the different steel grades, the maximum values of the force are shown in the following table; all these values have a negative sign, also the lowest value is for steel 53 , while the largest value is for steel 50 .

Table 3: The maximu m force for the different grades at $900^{\circ} \mathrm{c}$.

\begin{tabular}{|c|c|c|c|}
\hline Material & Steel 50 & Steel 52 & Steel 53 \\
\hline Max Force & -2834.9 & -2966 & -3332.5 \\
\hline
\end{tabular}

at 50 PNG. The start of transformation occurred at $680 \mathrm{~K}, 1 \mathrm{Sec}$ and the end occurred at $1010 \mathrm{~K}, 90 \mathrm{Sec}$. 


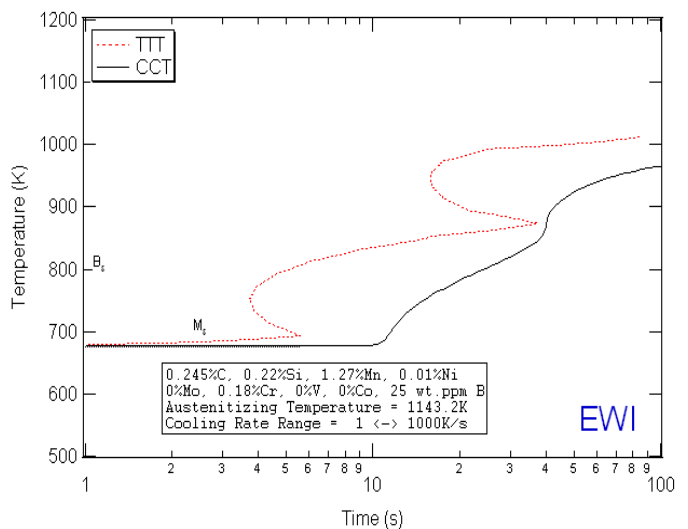

Figure 11: TTT and CCT for grade 50

For 52, Figure 11 shows that the beginning of transformation occurred at $680 \mathrm{~K}, 1 \mathrm{Sec}$ as well as the finish of transformation temperature being 1005 $\mathrm{K}$ which occurred at $100 \mathrm{Sec}$.

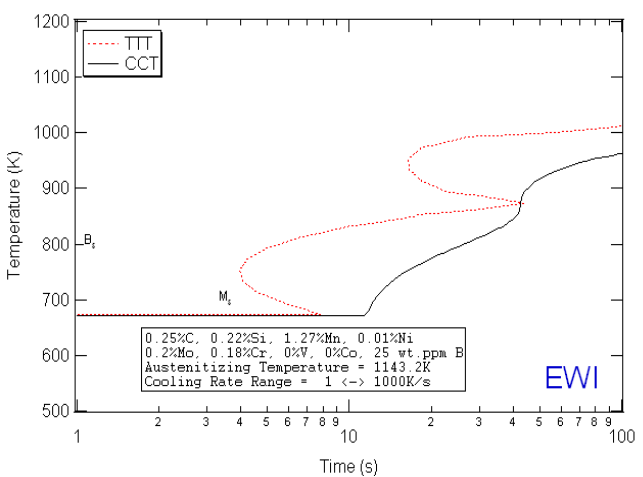

Figure 12: TTT and CCT for 52

The next figure presents the results for 53 where the beginning of transformation occurred at $680 \mathrm{~K}$, OSec, and the finish of transformation temperature was $1000 \mathrm{~K}$ and occurred at $100 \mathrm{sec}$.

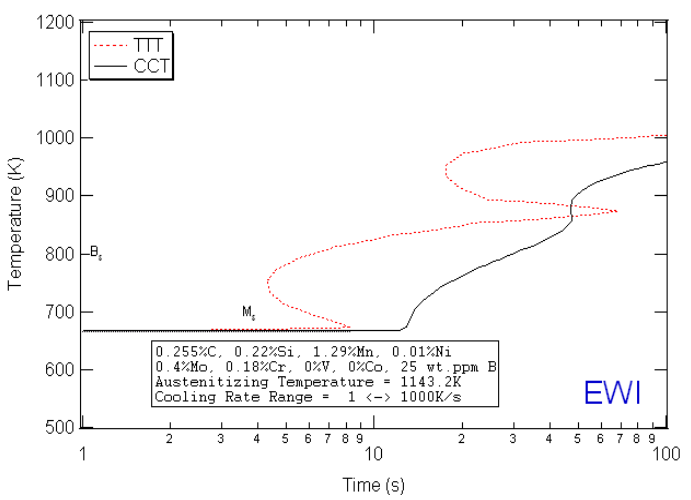

Figure 13: TTT and CCT for 53

The next figure is the CCT diagram that presents the relationship between time and temperature transformation corresponding to the begin and end of the transformations for the three kinds of steel: 50, 52 and 53 .

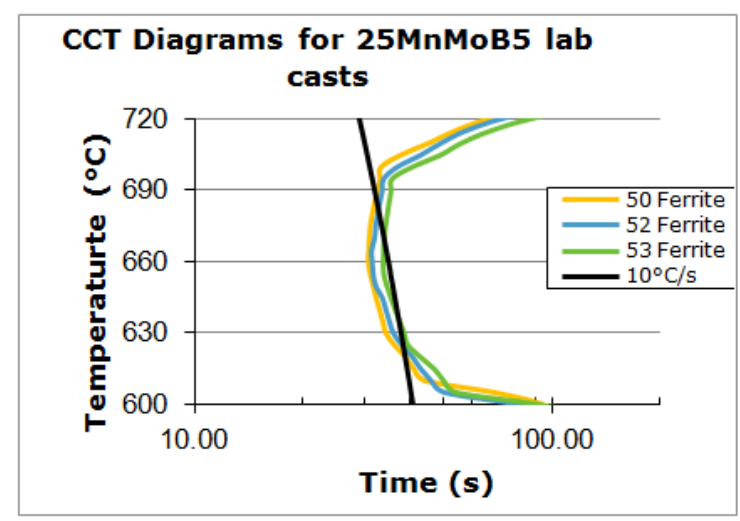

Figure 14: CCT diagram for all types of steel

The next figure is the TTT diagram, which presents the relationship between time and temperature transformation corresponding to the start and finish of the transformations for the three types of steel: 50 , 52 and 53.

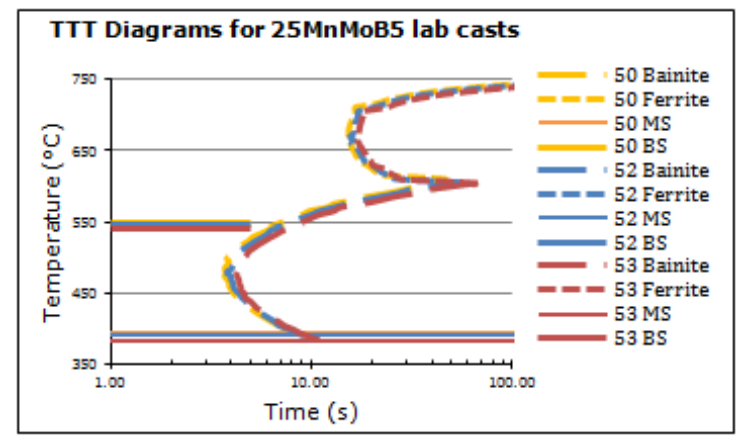

Figure 15: CCT diagram for all types of steel

The above mentioned methods are recommended to be used in investigating the hot rolling characteristics of boron steels with the variance of molybdenum additions. Shown in the five different pictures below, are the various microstructures of boron steel in different thermal treat ments:

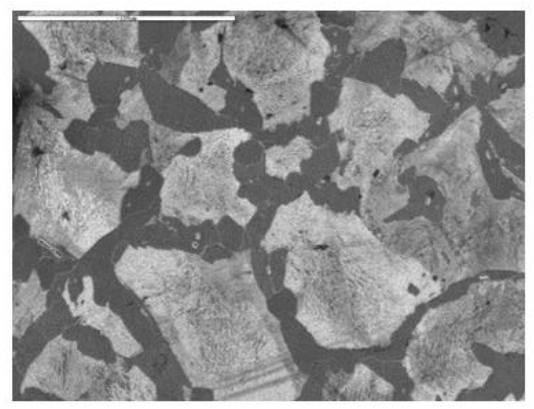

Figure 16: Microstructures of boron steel in different thermal treatments. Grade 50 in the as received condition. 


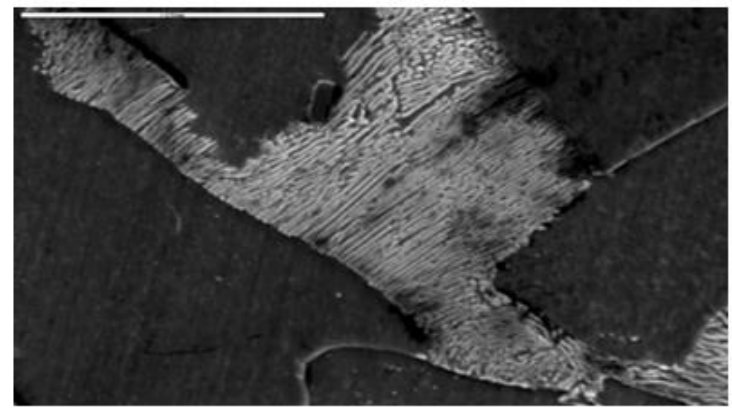

Figure 17: Microstructures of boron steel in different thermal treatments. Grade 50 in the as received condition

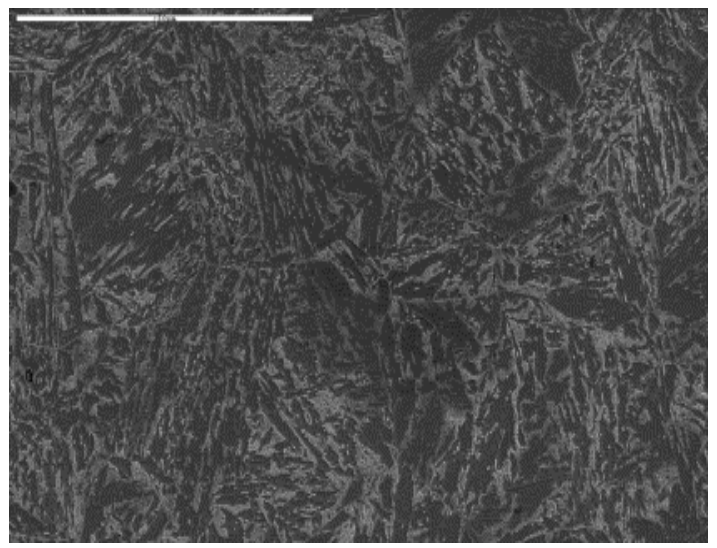

Figure 18: Microstructures of boron steel in different thermal treatments. Grade 53 in the as received condition

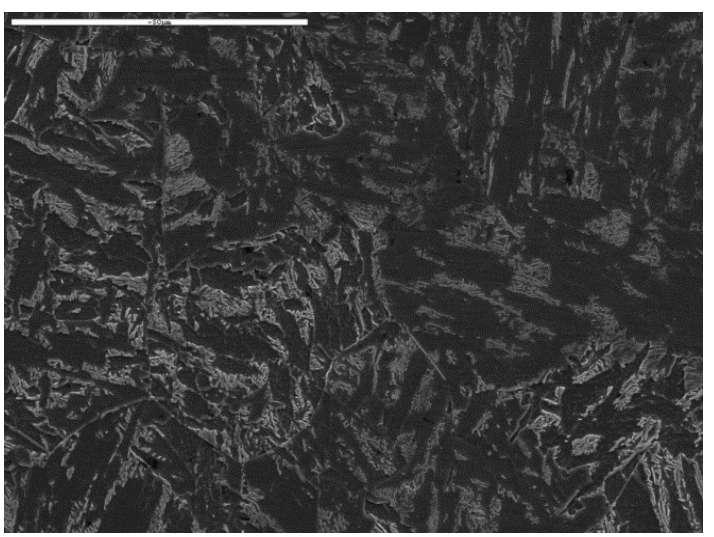

Figure 19: Microstructures of boron steel in different thermal treatments. Grade 50 in the as received condition

\section{CONCLUSION}

Steel material is considered to be the most important material that is used in several engineering applications due to it being a foremost element in the building of structures. Because of the increasing demand for vehicles safety as well as crash needs in industry, the use of ultrahigh-strength steels in components of safety and structural aspects is increased. The hot stamping process with the die cooling of boron steels was introduced at the end of the 1990s in order to produce some types of automotive parts such as bumper beams as well as door beams. This process of using boron steel helps to avoid some of the difficulties that are related to the use of other types of materials.

Boron steels are suitable for various applications. Molybdenum can be used as an alloy to ensure a high value of strength for the alloys of low steels and to enhance their properties, for example mechanical properties. These grades are useful in diverse industries since improving the mechanical properties of the steel will increase its performance.

In addition, the paper has discussed the Gleeble hardness test besides the microstructure before and after implementation of the hot stamping process. The stress-strain has been defined for a particular temperature range. Also, the paper has provided accurate TTT and CCT diagrams for the three grades that were used, which are steel 50, steel 52 and steel 53.

- The Gleeble experiment shows that the grades $(50,52,53)$ were heated to $1200^{\circ} \mathrm{C}$ at $10^{\circ} \mathrm{C} / \mathrm{Sec}$, where the Hold was done for $1 \mathrm{Min}$. Then the grades were cooled to $1100^{\circ} \mathrm{C}$ at $10^{\circ} \mathrm{C} / \mathrm{Sec}$. When the temperature reached $1100^{\circ} \mathrm{C}$, the compress occurred to a strain of about 0.3 at a strain rate equal to 1 . After that, the double hit was performed at three different temperatures, which are 900,850 and $800{ }^{\circ} \mathrm{C}$. Where the grade was cooled from $1100^{\circ} \mathrm{C}$ to one of the above temperatures at $10^{\circ} \mathrm{C} / \mathrm{Sec}$, it was compressed further to a strain of about 0.2 at a strain ratio of 1 twice. The cooling process continued until the grade reached $750^{\circ} \mathrm{C}$ at $6^{\circ} \mathrm{C}$ (it was supposed to be 10 , but it was only noticed later on that it was different, however it was consistent for each test). Then the cooling to 0 at $10^{\circ} \mathrm{C} / \mathrm{S}$ occurred (until controlled cooling is lost $\left.\sim 200^{\circ} \mathrm{C}\right)$.

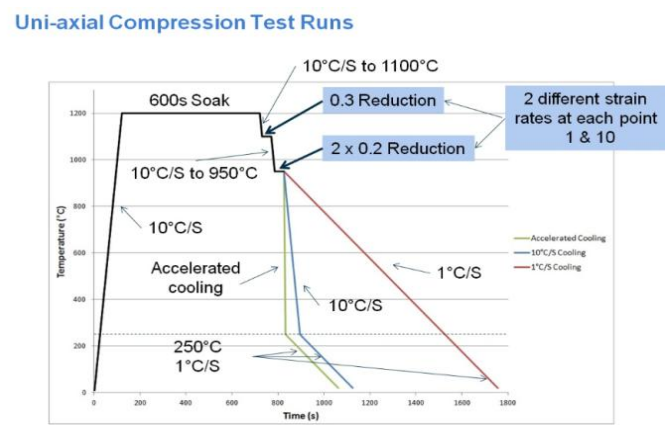

Figure 20: Uni_axial compression test 
- The microstructure experiment changed with additions of Mo in the cooling conditions and it change at compressions at different temperature between each grades.

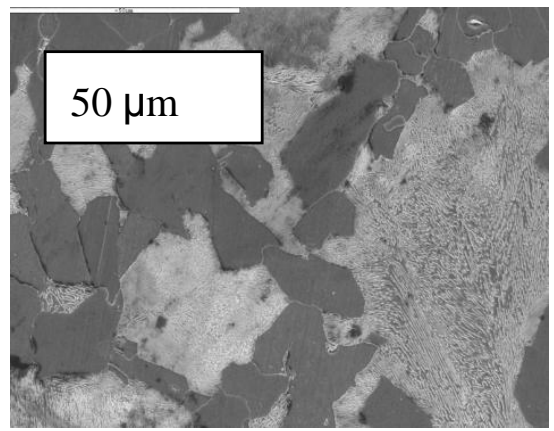

Figure 21: Grade 50 in the as received

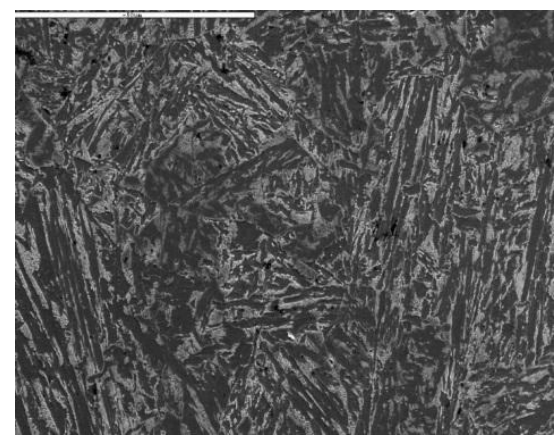

Figure 22: Grade 52 in the as received

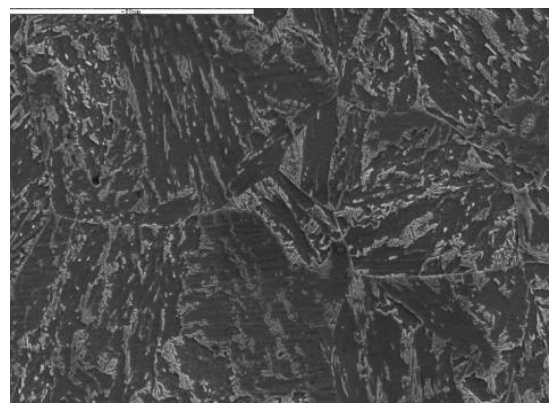

Figure 23: Grade 53 in the as received

- The hardness testing increasing with additions of mo in the cooling condition for the grades ( 50-200, 52-250, 53-300) HV

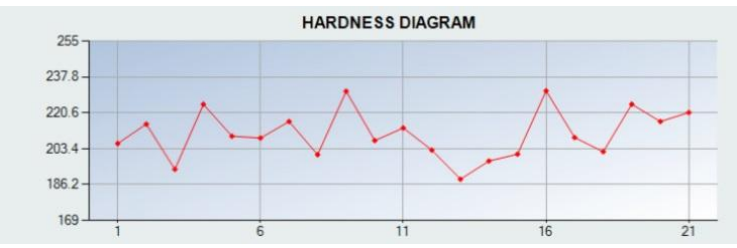

Table 4: Hardness testing for grade 50

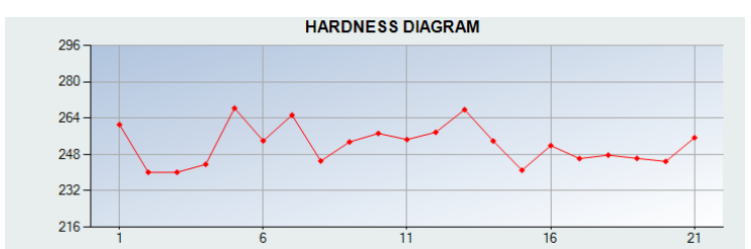

Table 5: Hardness testing for grade 52

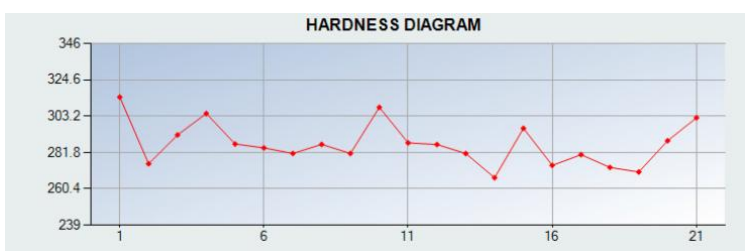

Table 6: Hardness testing for grade 53

\section{REFERENCES}

[1] H. a. O. R. Gu ler, (2014). "Comparis on of hot and clold stamping simulation Usibor 1500 prototype model". Indian Journal of engineering \& Material Science, 21: 387-396.

[2] A. a. P. L. Naganathan, . (2012). "Hot Stamp ing”. Sheet Metal Forming-Processes and Applications.

[3] T. ALTAN, (2006). "Hot-stamping boronalloyed steels for automotive parts". Stamping Journal: 40-41.

[4] H. a. T. A. E. Karbasian.

[5] S. \&. L. B. (. Frydman, . Properties of Boron Steel After Different Heat Treatments. Wroclaw, Poland. Hwang, B., Suh, D.-

[6] \&. K. S.-J. W., (2011). Austenitizing temperature and hardenability of low-carbon steels. Scripta Materialia, 1-12..

[7] H. Mohrbacher, (2010). Principal effects of Mo in HSLA steels and cross effects with microalloying ele ments. Schilde, Belg ium. .

[8] M. S. V. K. M. M. A. \&. Y. S. Nourami, . (2012). On the Microstructural Evolution of 4130 Steel During Hot Compression. Recent Patents on Materials Science, 74-83..

[9] B. S. D.-W. \&. K. S.-J. Hwang, (2011). Austenitizing temperature and hardenability of low-carbon steels. Scripta Materialia, 1-12.

[10] A. J. N. \&. J. B. Deva, (2012). Effect of Austenitising Temperature and Cooling Condition on Mechanical Properties of Low Carbon Boron Containing Steel.

[11] D. d. s. Inc, (2015). Gleeble Systems: Defining a New Era in Thermal-Mechanical Physical Simulation and Testing valied at <http://gleeble.com/> accessed at 28/4/2015.. 